\title{
Using Case Study as a Teaching and Learning Strategy in the Teaching of Economics: A Literature Review
}

\author{
Molise Habasisa \\ Clubview Secondary School, Phuthaditjhaba, South Africa \\ Email: molisehv@gmailcom \\ Dipane Hlalele
}

School of Education Studies, Faculty of Education, University of the Free State, Qwaqwa campus, Phuthadithaba, South Africa

Email: hlaleledj@qwa.ufs.ac.za

Doi:10.5901/mjss.2014.v5n23p999

\section{Abstract}

The purpose of this article is to provide a reflective discussion, using literature review, on the use of case study as a teaching and learning strategy to improve academic learner performance in Economics. Guided by the social constructivism paradigm, we attempt to provide an exposè on the need for the use of case study as a teaching and learning strategy; the concept of case studies; conditions for the successful implementation of the case study as a teaching and learning strategy; barriers to using case study as a teaching and learning strategy and how to overcome them; as well as evidence suggesting that the strategy may improve academic learner performance in Economics.

Keywords: case study, social constructivism, learner performance; Economics; higher education

\section{Introduction}

Many schools, especially rural schools, experience the problem of poor academic performance in Economics (Reilly \& Bachan, 2005:86; Van Wyk, 2010a:83; Van Wyk, 2010b:111, Van Wyk, 2011:117). Learners are unable to develop the real life skills they need to succeed academically, to be able to think and choose responsibly as consumers, savers, investors, citizens, members of the work-force, and be effective in a global economy (Van Wyk \& Alexander, 2010). Disparities in schools are determinants of lower performance in rural schools and these schools offer lower quality of education that contributes to lower achievement because of fewer resources (Sandy \& Duncan, 2010:298), teachers lack certification and they teach in areas outside their major subjects. The challenge of poor academic performance in Economics is not unique in South Africa, but it also affects schools globally. Poor academic performance in schools in the United States of America (USA) manifests itself by not providing teachers with the necessary support and professional development to implement instructional practices accurately, consistently, and contextually and to relinquish ineffective and inefficient practices (Colvin, Flannery, Sugai \& Monegan, 2009:95). Factors such as subject combination, age on admission, parental involvement and the location of school account for poor academic performance in Nigerian schools (Oladokun, Adebanjo \& Owaba, 2008:72). In Lesotho little or lack of emphasis on teacher training created problems in teaching (Johnstone \& Chapman, 2009:139). This problem is also prevalent in South Africa, issues like outdated teaching practices and lack of basic content knowledge, mathematical illiteracy and language barrier results in poor academic performance (Miji \& Makgato, 2006:254; Van der Merwe, 2007:126). These problems necessitate a need to come up with interactive teaching and learning strategy.

\section{Conceptual Framework}

The conceptual framework used to understand the use of case study as a teaching and learning strategy for improved academic learner performance in Economics is social constructivism. We have adopted this framework because it will help learners construct knowledge, based on their own experiences, in an active process facilitated by a teacher, rather than being lectured about predetermined knowledge (Wright \& Grenier, 2009:255). Knowledge construction has the potential to encourage teaching, and views of school learning that are dynamic, interactive, and expanding rather than 
static and prescribed. We strongly believe that positive teaching and learning can be ensured if learners are given an opportunity to apply the existing body of knowledge in a manner that they are able to make sense out of Economics concepts or socio-economic issues. This paper intends to use case study to improve learner academic performance in Economics and we have located the use of case study within social constructivist approach. Successful learning from case study employs a social constructivist approach to develop knowledge in learners who are engaged in a process of problem-based, meaning-making learning - building on and benefiting from the knowledge of case discussants (Badger, 2010:504). With no one right answer or a particular viewpoint, the objective of a case discussion is not to arrive at a right answer, but to examine all the complex issues raised in the case through a learning process that underscores the contributions of learners and teachers.

Social Constructivism claim that truth is relative and that it is dependent on one's perspective (Sapire \& Reed, 2011:198), this paradigm recognizes the importance of the subjective human creation of meaning, but doesn't reject outright some notion of objectivity. Social Constructivism is built upon the premise of a social construction of reality. We are using social constructivism because we want to ensure close collaboration between us and the participants, while enabling them to tell their stories in real-life settings. Through these stories the participants are able to describe their views of reality and this enables me to better understand the participants' actions. Using social constructivism approach as our conceptual framework will enable learners to become conscious of their own learning so that they overtly develop their understanding of the teaching practices they experience in order to purposefully link the manner in which they learn in a given situation with the nature of the teaching itself (Sapire \& Reed, 2011:199), although there are diverse interpretations of social constructivism as a theory of learning teachers and learners are supposed develop their own noble ways of knowing and acquire existing human knowledge which they reconstruct in developing their own knowledge systems.

According to Ngcobo (2008:8) the crux of social constructivism is in the active construction of meaning through interactions with the social and the physical environment. Social constructivism is a deeply textured perspective on learning, because it has both theory and practice at play. Without the social learning aspect, social constructivism could be problematic for teachers. Diversity is respected and all learners are recognised participants in the learning process. It emphasises the importance of interaction between learners in the learning process, is valuable because learners learn through interacting with knowledgeable others. This is closely related to the notion of "creative learning" as a group system where the success of the learner is dependent on the success of the group (Makoelle 2013:55). According to Ngcobo (2008:9), the guidelines to how knowledge construction can be facilitated include; creation of real-world environments that promote contextualized learning; Provision of tools and environments that help learners interpret the multiple perspectives of the world; Provision of multiple representations of reality; and focus on knowledge construction and not reproduction.

A collaborative, interactive, social constructivist learning environment, as opposed to passive learning environment is found to be better to help learners learn more actively and effectively (Ruey, 2010:706). According to Ruey a social constructivist learning arose from Piagetian and Vygotskian perspectives, emphasising the impact of constructed knowledge on the learners' active and reflective thinking. While Piaget focuses more on individual cognitive social constructivism, Vygotsky stresses that the sociocultural systems have a major impact on an individual's learning. He further assert that in social constructivism theory, knowledge is socially situated and constructed through reflection on one's own thoughts and experiences, as well as other learners ideas. Therefore, by using case study in the social constructivist learning environment we will encourage learners to actively engage in learning to discuss, argue, and negotiate ideas and to collaboratively solve problems and teachers to design and provide the learning context and facilitate learning activities. Social constructivism teaching methods, such as case-study teaching require learners to construct or create knowledge proactively by engaging with realistic problems. Three rationales for adopting social constructivism in using case study are that it may: help learners to construct a deeper understanding of theoretical concepts that is better connected with practical experience; help learners to develop skills in performing the routine problem-solving tasks and develop learners' knowledge creation capacity (Hanson \& Sinclair, 2008:169).

According to Van Wyk and Alexander (2010a:161) social constructivism implies that learners are encouraged to construct their own knowledge in realistic situations with others instead of in decontextualized, formal situations where they work on, such as propagated in traditional textbooks. The central idea behind using social constructivism during case-based teaching is that we want learners to build new knowledge upon the basis of previous learning. We also want the learners to show active participation in the problem solving and critical thinking abilities in learning activities which they find relevant and engaging. Hughes, Huston and Stein (2011:8) suggest that case studies are suitable learning tools to stimulate experiential learning. Experiential learning is simulated when the learners engage in focused problem solving. 


\section{Understanding the Concept 'Case Study'}

Case study is defined as a story with a hidden message or a narrative that describes an actual or realistic situation in which an individual or a group has to make a decision or solve problems (Killen, 2010:323). Economics as a subject, requires learners to be problem solvers and the use of this approach will enable them through case discussion to identify and solve problems present in the case. This will help produce learners who are critical thinkers and who can bridge the gap between Economics theory and turn it into practice. Tal (2010:143-144) defines case study as a meta-skill that integrates cognitive perceptions, self-regulation skills, and interpersonal relationships with learners and teachers. It is also perceived as a cyclical process that includes advance planning, implementation, assessment during the implementation, and a final evaluation that takes into account factors related to the learners and their environment, intended to bring about progress in the activities carried out for the learning and emotional well-being of the learners in the class. During the use of case study we will lead the class, both learners and teachers toward achieving the socio-emotional welfare and learning of the learners.

Case-based learning has been extensively used in several areas of professional education such as law, medicine, clinical health, and business as an alternative to the traditional lecture as an instructional method (Lee, Lee, Liu, Bonk \& Magjuka, 2009:179-180). The idea is to move away from teacher centred teaching methods to interactive methods to enable learners to learn through real-life scenarios and settings. According to Dart, Nkaotseng, Chizwe and Koya (2010:79) case studies are likely to have the following characteristics: they tend to employ multiple methods of data collection and analysis; they involve individuals/actors/organisations in a particular context/setting; they are empirical in that they collect data and analyse events/phenomena in a particular case; and the presentation of the case tries to capture the richness of detail of the given situation.

Case study is designed to focus on learner-centered education, prioritize problem-solving, facilitate early economic exposure, and foster life-long and community-oriented learning principles, Ngcobo (2008:22) have identified several benefits of case study, which are:

Promotes deep, rather than surface learning; enhances and retains self-directed skills; the learning environment is more stimulating; promotes interaction between learners and teachers; promotes collaboration between disciplines; more enjoyable for learners and teachers; promotes retention of knowledge; and improves motivation.

Case studies stimulate dialogue, careful listening and collaborative problem solving (Badger, 2010:504). Case study bridges a gap between theory and practice (Olkum, Altun \& Deryakulu, (2009:153). In this paper case study as a proposed teaching method will enable learners relate what they have learnt from Economics content and relate it to their everyday life and their way of living in their respective communities. Our role will be to help learners on how to translate theory into practice through the use of case study. According to Roushias, Barton and Drake (2009:39) parents needs to be involved in the education of their children to identify issues, problems and ideas that are embedded in the case environment by having them pose their questions from multiple perspectives, using the various information resources provided.

Choi, Lee and Kang (2009:936-937) define case study as a teaching method which requires learners to actively participate in real or hypothetical problem solutions, reflecting the kinds of experiences naturally encountered in the discipline under study. This is the use of case study to improve leaner academic performance in Economics. This method is suited for teaching the essential skills of analysis, decision making, critical thinking and problem solving in their professions. Here we argue that there is variety of ways to organize learning activities around cases in a case based learning and the different learning events organized around cases may cause different learning experiences. Choi, Lee and Kang (2009:936-937) further points out that there are three kinds of cases: representative cases, real-life stories and challenge cases. In the representative case, learners can watch the case through a video screen. Then, they watch the expert's reasoning video for the six steps of the decision making process of the case, which are: identifying problem cases, assessing situations, goal setting, gathering solutions and evaluating the solutions. After watching the experts reasoning, learners summarise what they have observed according to the guiding format provided in the reasoning and decision report. While watching representative case videos or expert reasoning videos, or while writing reports, learners can access various information resources. All of the learning resources are updated according to the current decision making.

Case-based instruction emphasizes the transformation of theoretical knowledge into theoretically informed practice. A major strength of the case study method is that its focus encompasses richly detailed contexts (Swanson \& Morris, 2010:94). Case study represents another way to facilitate the learning process of students. Its main advantage is to link theoretical concepts and economic situations to be solved, allowing Economics learners to take better advantage of their grounding in Economics to solve complex problems. It promotes hypothesis generalization, consolidation and 
integration of learning activities and contributes to develop team working skills (Van Dijken, Thevoz, Kupper, Feihl, Bonvin \& Waeber, 2008:131).

Heitzmann (2009:523) asserts utilizing higher order skills; applying theoretical knowledge to classrooms, schools and the wider community; using self-analysis skills; enlightening learners to the complex nature of teaching and analysing educational and societal issues as advantages of using case study.

A case with multiple problems (Swanson \& Morrison, 2010:96) enables the teacher to focus on problem clarification as a key learning outcome. Consequently, this approach is very popular when teaching subjects such as Economics, where it is desirable to encompass the problems involving a variety of subject matter fields. The process of identifying the problem, encouraging possible solutions, establishing criteria to be incorporated in the solution that is selected, and selecting the problem along with the supporting rationale makes for an important experience. According to Van Wyk (2011:127) the following steps should be borne in mind when the case study is introduced in Economics: (1) plan the specific outcomes for using case study. Identify what objectives are for the lesson and the use of the specific cases. The objectives for using the case to a specific topic could either be to promote critical thinking or class discussion on contemporary economic issues. (2) Analyse the specific case by applying different formats or structures such as case extracts to accommodate learning styles. Perhaps they just need a way to organise it that suits their strength. (3) Integrate other subjects to the case study or use them to segue into something else. (4) Use a transparency overlay as a visual guide in analysing the case. Ask learners to identify the skills they learned and how that skill can help them with other areas. (5) Use graphic organisers to help learners analyse the context and or the message being conveyed in economic cases. (6) Ask learners to create their own scenarios and interpretations of an economic event such as budget. (7) Use quotes, either from newspapers or economic magazines. (8) Use case studies to initiate class discussion, role playing, simulations, dialogue, debate and essay writing. (9) Ask learners to visit to visit each other's cases and see if they can decipher meaning to it. May be some leaners are naturally better at analysing the case themselves. Role play or simulations is one possible venue-having learner's act out potential scenarios. (10) Be prepared to facilitate discussions that may lend themselves well for debate. Try not to convey your own position-strive for neutrality of the teacher. (11) Implement your assessment strategy or tool to see if the leaners achieve the outcomes or objectives of the lesson. (12) Debriefing the case. The fact that the twelve steps are listed in a particular order provides for a sequential implementation but does not necessarily mean that they should be applied in a similar manner in all contexts, since teaching and learning contexts are diverse.

\section{Review of Literature}

\subsection{The need to use case study as a teaching and learning strategy}

In South Africa, Van Wyk (2011:183) indicates that teachers do not present their subject in ways that are meaningful because of lack of content knowledge. Learners are not effectively engaged in the subject and interest in the learning content is not evoked. I argue that Economics teachers will be enabled to initiate teaching and learning effectively so that knowledge, skills and positive attitudes may be optimised among learners in their response to economic environment. Hlalele (2014:107) argue that teachers' exposure to suitable teaching strategies is limited, there is no specific teacher training on the use of appropriate teaching and learning strategies in their classroom. He further asserts that teachers are faced with high workloads owing to planning and assessment requirements. He also argues that the learning materials are not always available and if there were not suitable for selfstudy. Even though rural teachers generally report a higher level of job satisfaction than their urban counterparts, rural communities have a higher number of less-qualified teachers and often lose their most experienced employees to higher-paying posts in nearby urban areas (Hlalele 2014:108).

Economics teachers are still unable to create a teaching-learning environment in which learners will be able to master critical and developmental outcomes (Van Wyk, 2010:111). The use of case study to improve learner academic performance will foster working relations between teachers and learners to create an enabling environment in which Economics outcomes are achieved for improved results. Wadesango (2011:267) argue that some teachers in Zimbabwe complain bitterly about non-participation in decision making in different aspects like discipline policies, school-based promotion, selection of learning materials, choice of curriculum, ordering of textbooks and teaching load allocation at the school level. In Lesotho Johnstone and Chapman (2009:132) asserts that lack of teacher workshops/training and qualifications seriously impinge on the work lives of teachers.

The study by Muraya and Kimamo (2011:728) in Kenya shows many factors contribute to poor academic peformance in Economics. These factors include: learners attitude towards the subjects which the perceive as difficult; inappropriate teaching approaches that are teacher rather than learner-centred; inadequate mastery of teaching subject 
content by some teachers; inadequate teaching and learning resources such as textbooks and library; poor terms and conditions of service for teachers; and heavy teaching loads among others. According to Olatoye and Adekoya (2010:19) in Nigeria, teachers are still using traditional methods and they do not tend to foster critical thinking, creative thinking and collaborative problem solving, and teachers are being ever more challenged to find effective ways to meet diverse needs of their learners (Asikhia 2010:234). According to Reche, Bundi, Riungu and Mbungua (2012:129) the adequacy and use of teaching and learning materials affects the effectiveness of a teacher's lesson. Teaching and learning resources enhances understanding of abstract ideas and improves performance. They argue that inadequacy of learning resources like text books, library books, wall maps and the exercise books account for poor academic performance (Kimani, Kara and Njagi 2013:4). This makes learning of subjects like Economics very abstract to the learners and could be a factor contributing to poor performance in national examinations (Karue \& Amukowa 2013:92).

Asikhia (2010:230) believe that the falling level of academic achievement is attributable to the attitude of some teachers to their job is reflected in their poor attendance to lessons, lateness to school, unsavory comments about student's performance that could damage their ego, poor method of teaching and the likes affect pupils' academic performance. Gakure, Mukuria and Kithae (2013:928) further argue that there is urgent need to undertake comprehensive evaluation of teachers in public schools, simply because their professional performance cannot be separated from their pupil's outcomes. He adds that there is need to invest regularly in the development of teachers, as teachers need access to continuous and effective updating and updating systems. Kimani, Kara and Njagi (2013:3) found that teachers' experience and educational qualifications were them prime predictors of learners' academic achievement. According to Popil (2011:202) several barriers to learning have been identified in lecture based classrooms in USA. These barriers stem largely from the unidirectional nature of the interaction between teachers and learners. In large lecture-based classes, the teacher typically transmits information while the learners take notes in a relatively passive manner. Popil (2011:207) argue that teachers are still using out-dated teaching strategies.

\subsection{Approaches to using case study as a teaching and learning strategy}

\subsubsection{Strategic planning}

According to Ndimande (2005:11) planning is an indispensable part of on-going school improvement. It enables planners to concentrate their efforts on improving learner academic performance. To be effective, schools need to become proactive rather than reactive to the changing environment. Planning for effective learning is a critical feature for the improvement of the academic performance of a leaner. He further state that for an educational institution, strategic planning is essentially a matter of bridge-building or mapping the route between the perceived present situation and the desired future situation. However, Shangase (2013:26) maintains that the strategic planning is critical for Total Quality Management (TQM) in education, because strategic planning maps the direction in which the country is heading. It comprises the clearly articulated goals that all the stakeholders collaboratively formulate and if implemented properly will yield a desirable outcome. Strategic planning encompasses six important steps namely, the team, common vision, SWOT analysis: priorities, monitoring/evaluation. These steps are discussed in detail below.

\subsubsection{Teamship}

Working as a team is a cornerstone for any improvement initiatives within an educational institution (Tsotetsi 2013:71; Ndimande 2005:10). These authors argue that for schools to enhance LAP, it is crucial to have in place a team that will work towards high standards and that excellent LAP endeavors are a norm. These teams come up with strategic initiatives that will lead the school towards action-oriented goals. Shangase (2013:24) also attests that in 2009, the Minister of Basic Education appointed a Ministerial Task Team to review the implementation of the NCS Grades R to 12. Its brief was to identify the challenges and pressure points that impacted negatively on the quality of teaching in schools and propose mechanisms that could address these.

\subsubsection{Common vision}

According to Ndimande (2005:11), strategic planning involves a value-driven vision. This approach emphasises that for the school to be successful all its activities must be driven by the values and the vision of the school. These values should be developed and owned by the principal and all major role players namely: parents, teachers, non-teaching staff, learners and the community in general. These role players must participate constructively in the development of the 
vision of the school. I argue that if parents, teachers and learners are all properly involved, they are most likely to support the SMT in their attempt to achieve the best for all learners. Tsotetsi (2013:74) argue that an ideal vision can help us identify useful strategies and tactics for improvements. Strategic planning is not a prescriptive, rigid, linear, lock-step, authoritarian process, nor is it built on hunches and raw feelings, but rather it encourages the educational purposes, mission and vision of the school to be accomplished. It provides blueprints for results-oriented progress and renewal. Shangase (2013:27) also argue that the vision cannot be realized if the head fails to convert the vision into policy and practice. He states that the whole school community should in some way be involved in the development of a vision. The vision should show the school community and the outside world what the culture of the school is or should be the school's values and the direction the school wants to move toward (Ndimande 2005:12).

\subsubsection{SWOT analysis}

According to Ndimande (2005:14) the action plan helps the school to move towards its vision. This is done through practical and concrete projects. The action plan for the year should show the top five priorities that were chosen by educational practitioners. He argues that a mere analysis of the strengths and weaknesses of the school as well as the opportunities for and threats to the school, is pointless unless the relevant stakeholders can formulate an action plan for school improvement based on this analysis. Tsotetsi (2013:76) suggests therefore that a modus operandi must be formed to bind together all three factors, namely vision, SWOT analysis and prioritisation so as to formulate an action plan which is in step with the mission of the school. A school can be said to function adequately, but a conscious action plan to eradicate weaknesses is an important strategy to support the vision for improved learner academic performance. The action plan is seen as a step to minimize future problems.

\subsubsection{Prioritisation}

In accordance with a school's mission statement, a school exists to provide quality education for all its learners. In order to realise the mission statement, goals need to be set and prioritised. Staff involvement in setting priorities is an integral part of the enhancement of the academic performance of learner (Tsotetsi 2013:82). Ndimande (2005:15) stipulates that setting priorities should be about reconciling differences in the process of improving academic performance of a learner. He states further that prioritisation is an important component of an effective development programme. In the school situation, prioritisation helps SMTs to focus; it gives room to maintain strengths and to eradicate weaknesses in favour of better academic performance (Shangase 2013:26). She maintains that there should be consultation about possible priorities. Consultation will lead to long list of priorities that have to be selected for the first year of the plan.

\subsubsection{Monitoring}

To ensure that the intervention towards improving learner academic performance succeeds, the team had to put mechanism to monitor and evaluate the progress (Tsotetsi 2013:100). The progress in this regard was monitored by the principal, teachers, the chairperson of the SGB and parents. The hard work, patience, clear purpose of the team, open communication between the team and participants, clear roles and responsibilities, strong relationship between the team and other teachers, and a willingness to share information and listen to other people as well as participation made it possible to monitor closely and reflect on the progress made.

\subsection{Conditions for implementing of case study as a teaching and learning strategy}

In South Africa, Van Wyk (2010:111) indicates that teacher are required to create a teaching-learning situation in which learners will be able to master critical and developmental outcomes, high levels of knowledge, skills and positive attitudes in the domain. Learners have to be enabled to identify problems and find solutions to these problems by means of creative and innovative thinking in real-life situations. Through this I want to enable teachers to initiate teaching and learning effectively so that knowledge, skills and positive attitudes may be optimised among learners in their response to the economic environment. The learners are supposed to learn in small groups and are expected to talk, question, learn and respond during the sessions (Ngcobo, 2008:19). A teacher facilitates the learning process for each group and much of the learning is learner centered, problem-based and self-directed. The teacher's role is that of facilitator. Throughout the case discussion, they are expected to critically analyze, clarify and debate ideas, issues and diverse viewpoints. Therefore there has to be active communication, with the possibility of disagreements among the group members. 
Van Wyk (2011:183) contends that Economics teachers should strive to present their subject in ways that are meaningful and lecture centered. If this can be achieved, learners are engaged effectively in the subject, and an interest in the learning content may be evoked by establishing excellent modes of teaching, such as cooperative learning, the Economics teacher may create an optimal learning environment to enable learners as workers to transfer knowledge and skills into the workplace. In Nigeria, Olatoye and Adekoya (2010:20-21) indicates that case study should be applicable to classroom activities to facilitate learners access to the mastering of Economics concepts to create cooperative pleasant atmosphere, enhance peer relations and also increase academic achievement of learners.

According to Ifamuyiwa and Akinsola (2008:572) case study enables the majority of learners in a class to learn at their own pace and provide opportunity for immediate feedback. The basic premise is that with the learners being in control of instruction, it affords them the opportunity to have time to think things through, structure the task of learning and to decide on the meaningfulness of what is learned. The learning content in Economics is presented in a well-arranged and organized form that lead the learners from a body of known principles to the unknown, from simple to complex concepts within the same content area. In Kenya, Muraya and Kimamo (2011:730) assert that in case learning environment, learners interact, assist one another with learning tasks, and promote one another's success.

According to (Roushias, Barton \& Drake, 2009:39) in USA, parents needs to be involved in the education of their children to identify issues, problems and ideas that are embedded in the case environment by having them pose their questions from multiple perspectives, using the various information resources provided. They should also provide evidence and supporting information gathered throughout their interaction with the environment, which will help them shape informed suggestions or solutions to their initial questions or problems as well as other problematic solutions. By using case study as a teaching strategy I want parents to be actively involved in the education of their children, by assisting them with homework and other written tasks, and with discipline where needed. Swanson and Morrison (2010:102) indicates that besides acquiring skills, the fact that case studies can be used to illustrate and understand decision-making, means that cases studies can be used to improve learner academic performance in Economics.

Hege, Ropp, Adler, Radon, Masch, Lyon and Fischer (2007:796) in their study emphasizes that teachers need to motivate their learners positively by getting them to participate in interactive seminars and case development; communicate to them in working through the case. In Sweden, the study by Jernquist and Svalenius (2007:815) shows that during case-based learning the teacher acts as a facilitator of discussion and of learning more than as direct source of information while the learners lead the session themselves with a chosen secretary and chairman. Dori and Herscovitz (2005:1418) states that developing a case study is a time consuming endeavor, while much less time is required to for its implementation. I want to provide mechanism for allowing learners to practice decision-making.

With cases learners interpret, analyze, inquire about ideas, and solve problems (Lee, Liu, Bonk \& Magjuka 2009:180). Problem centred cases, situations, and scenarios are used to examine and clarify the complexities of practices. As cognitive acts occur, learners begin to move from the status of a novice and gain the perspective of a professional within the field. Another key to successful case-based learning is facilitation, which leads to learner engagement. According to Bowe, Voss and Aretz (2009:835) learners are required to thoroughly review the cases in advance of the discussion sessions to identify the pivotal issues and to research additional knowledge needed. The preparatory work is done independently and in learner study groups and provides the foundation for a thorough discussion of key issues relevant to the problems posed in the case. The discussion session serves as the venue for learners to collaboratively apply learned principles and data analysis and evaluate the usefulness of various strategies to achieve optimal resolution of the problem posed.

Bowe, Voss and Aretz (2009:835) show that effective cases include sufficient ambiguity to accommodate a diversity of perspectives and interpretations of data, and a scenario which calls for critical analysis and a pressure to act. It begins with a non-threatening environment, open-ended invitation to learners to collectively compile a list of the problems outlined in the case. Learners' responses are tracked on a board, visually accessible to the class, throughout the discussion. Bowe, Voss and Aretz (2009:834) further indicate that case study should accommodate large discussion groups, exposes learners to a broad range of perspectives and problem solving strategies, achieves a balance between teacher-directed and learner centred learning, and is resource conservative in its demands on curriculum. According to Hughes, Huston and Stein (2011:9) suggest that experiential learning is stimulated when learners engage in focused problem solving. When the case concerns a difficult moment, problem solving opportunities abound. According to Markulis and Geneso (2007:85) case teaching can help learners learn to grow and become proactive in a dynamic environment. 


\subsection{Barriers to using case study as a teaching and learning strategy}

In South Africa, Scheepers and de Villiers (2000:179) assert that the major obstacle for the implementation of case study may be teacher's lack of experiences of using case study in group work dynamics. The role of the teacher of the teacher during case discussion changes to that of a mediator, facilitator and coach. The role of the learner changes to that of a collaborator and active participant, sharing knowledge with other learners rather than competing with them.

According to Schoeman, Schoor, van der Merve and Meintjes (2009:31) limitations of case study include lack of indepth learning and the unevenness of preparation among learners, another disadvantage of case study includes the considerable demands placed on teachers, because it is time consuming and it requires a full range specific skills from teachers in constructing and presenting an appropriate case-based challenge. According to Ngcobo (2008:22-23) excessive demands on time, relative inefficiency, variable teacher quality, the need for supplemental training, reduced acquisition of knowledge and implementation difficulties when class sizes are large places threats for the use of case study. Hughes, Huston and Stein (2011:10-11) assert that case study cannot represent all issues or experiences related to a sensitive topic. Case studies provide a rich context for discussion because they focus on specific details, but inclusion of those details means the case will differ from most people's experiences.

Tarnvik (2007:34) postulates that a major limitation of case method is the difficulty in constructing cases. In Economics education, the quality of a narrative may decide whether a case will arouse interest or not. The case should have a real background, irritate or trigger a willingness to discuss and concomitantly fulfill a scheduled learning objective. Another limitation is a need for teachers capable of chairing case sessions. Teaching skills include the ability to listen, catch signals in the classroom and make learners talk to each other. The method requires a substantial preparation time, and can be draining. Teacher development, retraining and supervision are required. Lyons (2009:30) states that harnessing the latent resource of case studies produced by practitioners is a worthwhile challenge, and multiple case studies that follow a broad template can be incorporated within larger studies. According to Tal (2010:151) the limitations of case study is that it is methodologically insufficient. Some learners need more guidance, particularly when they are in crisis. At a minimum discussion should be held between the teacher and learners. Case study excels at bringing us to an understanding of a complex issue or object and can extend experience or add strength to what is already known. Critics of the cases study note the difficulty in demonstrating that its findings are both generalizable and reliable because of the limited sample size (Swanson \& Morrison, 2010:94).

According to Popil (2011:205) although many observational outcomes are observed in learners learning when using the case method, there are also some limitations and obstacles that may be encountered. Disadvantages of case study include embedded author biases, a narrow focus on a dilemma facing a single person or group, and limitations in scope. Case studies are useful in situations requiring problem solving, but they are not appropriate in teaching concrete facts. Furthermore, developing cases is time consuming and may be difficult.

\subsection{Evidence for the use of case study as a teaching and learning strategy}

In South Africa, Scheepers and de Villiers et. al (2000: 179) asserts that case study have been used extensively in various research projects, it had a positive effect of such an environment on academic achievement, the development of social skills and interpersonal and inter-ethnic relations. According to Iputo and Kwizera (2005:388) the introduction of case study in teaching coincided with improved academic performance. A study in Kwa-Zulu Natal shows that case study encourages students to acquire and assimilate knowledge to use in their personal and professional lives and learn how to make their own unique contributions for expanding and improving their fields (Ngcobo, 2008:30).

In Kenya, there is evidence that case study promotes a more positive attitude towards the subject which is essential for enhancing learning. Muraya and Kimamo (2011:732) in their study confirms that the use of case study improve academic performance and interests towards the subject. In Nigeria, Oloruntegbe and Alake (2010:805) assert in their study, that case study provoked higher order and social skills and communication abilities in learners. It also challenges teachers and learners in the use of analytical thinking, gathering and analysing data to arrive at solutions to problems.

In the USA, Doucet, Vrins and Harvey (2009:570) points out that there is evidence to support that active learning approaches are effective in improving learning outcomes in Economics education. Among the various strategies proposed to promote active learning, case based teaching is considered to be effective in stimulating learners to synthesise, apply and integrate basic knowledge in the face of real-life situations and has been recommended for the teaching of Economics to improve learner performance. They further indicate in their study (Doucet, Vrins and Harvey 2009:570) that case study teaching strategy was adapted for the use during discussion. And when majority of learners 
responded correctly to questions with only one valid answer, there was less discussion needed than when there was a greater proportion of wrong answers, indicating that certain issues required clarification or further interpretation.

The study also provide evidence that the use of case study provided active learning environment during case based discussion in large groups of Economics learners and has an impact on learner and teacher motivation (Doucet, Vrins and Harvey (2009:574). It also shows that learners' who used case study during their discussion performed better in their final examinations. The study by Bowe, Voss and Aretz (2009:838-839) indicates that teachers were pleased with the quality of discussion and the classes overall performance. Learners had risen to the challenge of the format, met their preparatory responsibilities, and arrived in class willing to engage in a productive dialogue. Case discussions provided a valuable opportunity to appreciate the learners' capabilities to learn independently, synthesize and apply researched concepts, and integrate material from diverse disciplines in problem solving. The learners found the experience empowering by honing their skills for self-directed learning. The study by Lee and Choi (2008:495) shows that case based instruction was developed and implemented to allow prospective early childhood to teachers to be exposed to various dilemmas faced by practicing teachers.

\section{Concluding Reflection}

This paper has examined, through a review of related literature, how we can use case study as a teaching and learning strategy in the teaching of Economics. To achieve this, we looked at the need, conditions, barriers and the evidence from international, continent and SADC level in order to adopt their good practices in using case study. We also are of the view that conditions for implementation differ from one country to another, and this paper suggests an effective approach in implementing case study. We therefore conclude that case study as a teaching and learning strategy constitutes the base towards the creation of sustainable learning environment in schools.

\section{References}

Asikhia OA 2010. Students and Teachers' Perception of the Causes of Poor Academic Performance in Ogun State Secondary Schools [Nigeria]: Implications for Counselling for National Development. European Journal of Social Sciences, 13:228-242.

Badger J, 2010. Classification and framing in the case method: discussion leaders' questions. Journal of Further and Higher Education, 34(4):503-518.

Bowe CM, Voss J \& Aretz T 2009. Case method teaching: An effective approach to integrate the basic and clinical sciences in the preclinical medical curriculum. Medical Teacher, 31:834-841.

Colvin G, Flannery KB \& Monegan J 2009. Using Observational Data to Provide Performance Feedback to Teachers: A High School Case Study. Preventing School Failure, 53(2):95-104.

Dart G, Nkanotseng T, Chizwe O \& Kowa L 2010. Albinism in Botswana Junior Secondary Schools: A double case study. British Journal of Special Education, 37 (2):77-85.

Doucet M, Vrins A \& Harvey D 2009. Effect of using an audience response system on learning environment, motivation and long-term retention, during case-discussions in a large group of undergraduate veterinary clinical pharmacology students. Medical Teacher. Vol.31:570-579.

Hanson JM \& Sinclair KE (2008). Social Constructivist Teaching Methods in Australian Universities: Reported uptake and perceived learning effects: A survey of lecturers. Higher Education Research and Development, 27(3):169-186.

Hlalele D 2014. Creating Sustainable Rural Learning Ecologies in South Africa: Realities, lessons and prospects. Journal of Human Ecology, 45(2):101-110.

Hege I, Ropp V, Adler M, Radon K, Masch G, Lyon H \& Fischer M 2007. Experiences with Different Integration Strategies of Case-Based ELearning. Medical Education Unit, 29:791-797.

Hughes B, Huston T \& Stein J 2011. Using Case Studies to Help Faculty Navigate Difficult Classroom Moments. College Teaching, 59:7-12.

Heitzmann R 2009. Case Study Instruction in Teacher Education: Opportunity to develop students' critical thinking, school smarts and decision making. International Journal of Education, 128 (4):523-542.

Ifamuyiwa SA \& Akinsola MK 2008. Improving Senior Secondary School Students' Attitude towards Mathematics through Self and CooperativeInstructional Strategies. International Journal of Mathematical Education in Science and Technology, 39(5):569-585

Iputo JE \& Kwizera E 2005. Problem-Based Learning Improves the Academic Performance of Medical Students in South Africa. International Journal of Medical Education, 39:388-393.

Johnstone CJ \& Chapman DW 2009. Contributions and Constraints to the Implementation of Inclusive Education in Lesotho. International Journal of Disability, Development and Education, 56 (2):131-148.

Karue N \& Amukowa W, 2013. Analysis of Factors that Lead to Poor Performance In Kenya Certificate of Secondary Examination. International Journal of Social Sciences, 13(1):92-108.

Kimani GN, Kara AM, Njagi LW 2013. Teacher Factors Influencing Students' Academic Achievement in Secondary Schools. International Journal of Education and Research, 1(3):1-14.

Lee K \& Choi I 2008. Learning Classroom Management through Web-Based Case Instruction: Implication for Early Childhood Teacher Education. Journal of Early Childhood Education, 35:495-503.

Lee I, Lee SJ \& Kang J 2009. Implementing a Case-Based E-Learning Environment in a Lecture-Oriented Anaesthesiology Class: Do learning styles matter in complex problem solving over time? British Journal of Education Technology, 40(5):933-947. 
Lee SH, Lee J, Liu X, Bonk CJ \& Magjuka RJ 2009. A review of case-based learning practices in an online MBA program: A program-level case study. Educational Technology \& Society, 12(3):178-190.

Lyons H 2009. Case Study Research Methodology for Publishing Developments in ICT-Facilitated Learning in Higher Education: A perspective approach. Innovations in Education and Teaching International, 46 (1):27-39.

Makoelle TM 2013. Exploring Teaching Practices That are Effective in Promoting Inclusion in South African Secondary Schools. Unpublished Doctoral thesis. Manchester Metropolitan University.

Markulis PM \& Geneseo S 2007. From Case Presentation to Facilitation: How assessment changed the Capstone course. Development in Business Simulation and Experiential Learning, 34:85-89.

Mji A \& Makgato M 2006. Factors associated with high school leaners poor performance: a spotlight on mathematics and physical science. South African Journal of Education, 26(2): 253-266.

Muraya DN \& Kimamo G 2011. Effects of Cooperative Learning Approach on Biology Mean Achievement Scores of Secondary School Students. Education Research and Reviews, 6(12):726-745.

Ndimande BS 2005. The role of School Management Teams in Enhancing Learner Academic Performance. Unpublished Masters Dissertation. Umlazi: University of Kwa-Zulu Natal.

Ngcobo MN 2008 "On account of a basket": a socio-historical and ethnographic perspective on the development of multilingualism in South Africa. African Journal of Indigenous Knowledge systems, 7(1): 7-22.

Oladokun V.O, Adebanjo A.T, \& Owaba O.E.C, 2008. Predicting Students Academic Performance using Artificial Neural Network: A Case Study of an Engineering Course. The Pacific Journal of Science and Technology, 9(1):72-79.

Olkun S, Altun A \& Deryakulu, 2009. Development and evaluation of case-based digital learning tool about children's mathematical thinking for elementary school teachers (L-TEST). European Journal of Teacher Education, 32(2):151-165.

Olatoye R.A \& Adekoya Y.M, 2010.Effect of Project-Based, Demonstration and Lecture Teaching Strategies on Senior Secondary Students Achievement in an Aspect of Agricultural Science. International Journal of Educational Research and Technology, 1(1):19-29.

Oloruntegbe KO \& Alake EM 2010. Chemistry for Today and the Future: Sustainability through Virile Problem-Based Chemistry Curriculum. Australian Journal of Basic and Applied Sciences. Vol. 4(5):800-807.

Popil A 2011. Promotion of critical thinking by using case studies as teaching method. Nurse Education Today, 31:204-207.

Reche GN, Bundi TK, Riungu JN, Mbungua ZK 2012.Factors Contributing to Poor Performance in Kenya Certificate of Primary Education in Public Day Primary Schools in NAMIBIA Division. International Journal of Humanities and Social Sciences, 2(5):127-133.

Reily B \& Bachan R 2005. A Comparison of A-level Performance in Economics and Business Studies: How Much More Difficult is Economics. Education Economics, 13(1):85-108.

Roushias C, Barton AC \& Drake C 2009. The Design and Development of a Multimedia Case-Based Environment on Parental Engagement. Education Media International, 46 (1):37-52.

Ruey S 2010. A Case Study of Constructivist Instructional Strategies for Adult Online Learning. British Journal of Educational Technology, 41(5): $706-720$

Sapire I \& Reed Y 2011. Collaborative design and use of open educational resources: a case study of mathematics teacher education project in South Africa. Distance Education, 32(2):195-211.

Scheepers H \& de Villiers C 2000. Teaching of a Computer Literacy Course in South Africa: A case study using traditional and co-operative learning. Journal of Information Technology for Development, 9:175-187.

Schoeman JP, Van Schoor M, Van der Merwe LL \& Meintjies RA 2009. A Case-Based, Small-Group Cooperative Learning Course in Preclinical Veterinary Science Aimed at Bridging Basic Science and Clinical Literacy. Journal of South African Veterinary Association, 80 (1):31-36.

Shangase BB 2013. Strategies for the Implementation of Further Education and Training Learner Attainment Improvement Plan. Unpublished Masters Dissertation. Bloemfontein: University of the Free State.

St. Jernquist M \& Svalenius EC 2007. Problem-based Learning and the Case Method: Medical students change preferences during clerkship. International Journal of Medical Education, 29:814-820.

Swanson DA \& Morrison PA 2010. Teaching Business Demography Using Case Studies. Population Policy Review, 29:93-104.

Tal C 2010. Case Studies to Deepen Understanding and Enhance Classroom Management Skills in Preschool Teacher Training. Early Childhood Educational Journal, 38:143-152.

Tarnvik A 2007. Revival of the Case Method: A way to retain student-centred learning in a post-PBL era. Journal of Clinical Microbiology, 29:32-36.

Tsotetsi CT 2013. The Implementation of Professional Teacher Development Policies: A continuing education perspective. Unpublished Doctoral Thesis. Bloemfontein: University of the Free State.

Van der Merwe A, 2007. Using Blended Learning to Boost Motivation and Performance in Introductory Economics Modules. South African Journal of Economics, 75(1):125-135.

Van Wyk M 2010a. Do Student Teams Achievement Division Enhance Economic Literacy? A Quasi-experimental Design. Journal of Social Sciences, 23(2):83-89.

Van Wyk M 2010b. The Selection of Didactic Principles by Teachers in the Field of Economics: An Exploratory Factor Analysis. Journal of Social Sciences, 24(2):111-119.

Van Wyk M 2011. The Use of Cartoons as a Teaching Tool to Enhance Student Learning in Economics Education. Journal of Social Sciences, 26(2):117-130.

Van Wyk M, 2011. The Effects of Teams-Games-Tournaments on Achievement, Retention and Attitudes of Economics Education Students. Journal of Social Sciences, 26(3):183-193.

Van Wyk M \& Alexander 2010. Do Teaching Methods Presented by the National Council on Economics Education (USA) Enhance Trainers Learning Capacity in Economics Education? A South African Perspective. Journal of Social Sciences, 23(3):159-169.

Wadesango N 2010. The Extent of Teacher Participation in Decision-Making in Secondary Schools. School Leadership and Management, 30 (3):265-284.

Wright S \& Grenier M 2009. Examining Effective Teaching via a Social Constructivist Pedagogy: Case study. International Journal of Education, 130 (2):255-264. 